SiF 2020- The $11^{\text {th }}$ International Conference on Structures in Fire

The University of Queensland, Brisbane, Australia, June 24-26, 2020

\title{
A FRAMEWORK FOR RELIABILITY-BASED ASSESSMENT OF STRUCTURES IN POST-FIRE CONDITIONS
}

\author{
Tom Molkens ${ }^{1}$, Barbara Rossi ${ }^{2,3}$
}

\begin{abstract}
The actual codes on design procedures to assess the structural reliability in case of fire allows for a whole scope of methodologies to be used. At one end of the spectrum, the codes allow to simply combine design rules with member analysis using tabulated data or simplified calculation models. On the other extreme end of the spectrum, complex performance-based design approaches are proposed, the results of which are unique and highly dependent on the system's boundary conditions. Between those two extreme options, there are several other methodologies including the possibility to use probabilistic approaches. In this paper, reliability assessment of structures is based on the force-based method including temperature effects as well. This method is developed for single-bay portal frame and is based on the combined failure probability of 5 critical sections. All data needed to generate a probability density functions of the thermal actions on the structure is collected and described. Heat transfer equations of unprotected steel are used to calculate the profile temperature and reduction of mechanical characteristics during and after the fire. Coupling of the probabilistic-based thermal actions to the force-based method enables to create numerous simulations (Monte Carlo technique), and thus enable the system during and after a fire. This analysis is done for different load levels (self-weight), portal frame geometries and for several fire scenarios. Last, the post-fire behaviour of structural carbon steel single-bay portal frames is carefully investigated.
\end{abstract}

Keywords: Probabilistic analysis; steel portal frame; reliability assessment during fire; post-fire reliability

\section{INTRODUCTION}

While probability analyses have become common in structural engineering practice and form the basis of all structural codes at the component level [1], [2], their application to complete structural systems subjected to fire as well as the post-fire probabilistic assessment of structures is today a subject that has not yet been extensively researched. The subject became of interest in the last two decades, however it seems that the research is mainly focusing on concrete elements and remains limited to the component level rather than whole structures.

The need of a reliability-based assessment methodology for structures subjected to fire and in post-fire conditions is key to study the risks taken by fire brigades during a fire and the options available to building owners (and the society in general) when buildings have been submitted to a fire and are still standing. Ensuring adequate reliability is necessary if the reinstatement of buildings after a fire is being considered.

To analyse a risk associated with a certain load (fire, gravity load, live load, etc.), the probability theory should be used to quantify uncertain processes and statistical distributions should be used to

\footnotetext{
${ }^{1} \mathrm{PhD}$ researcher, KU Leuven, Belgium,

e-mail: tom.molkens@,kuleuven.be, ORCID: https://orcid.org/0000-0002-3401-9047

${ }^{2}$ Prof., KU Leuven, Belgium

e-mail: barabara.rossi@kuleuven.be, ORCID: https://orcid.org/0000-0001-6228-0309

${ }^{3}$ Prof, New College Oxford, UK

e-mail: barbara.rossi@new.ox.ac.uk, ORCID: https://orcid.org/0000-0001-6228-0309
} 
characterize the load, material, geometrical and thermal effects. The specified probability density functions (PDFs) giving the probability that the considered random variable falls within a specified range of values are different for all the mentioned statistical distributions and so Normal (N), lognormal (LN), Gumbel (GU) functions associated with determined parameters (such as the average and standard deviation) will have to be defined and combined. During and after the fire, the maximum reached (gas and steel) temperature will be needed, which is the reason why time-dependent Monte Carlo simulations will be used. This will then be coupled in a rather straightforward way to a simplified description of the limit state function $g$ of the system established based on the force-based method (FBM).

\section{OUTLINE OF THE PAPER}

Different methodologies are available to achieve a parametric study where different probability functions are used for all variables. At the system level, four building types with a unique shape are treated in a fully probabilistic way in [7] however without fire. Twenty-two failure modes are investigated for the system collapse, each time involving attainment of the plastic bending capacity. The limit state function for each failure mode is expressed as the difference between the internal and the external work. From the analysis, it appears that one mode was governing the design, i.e. the failure probability $P_{f}$ increased from $1.1 \cdot 10^{-7}$ to $1.16 \cdot 10^{-7}$, for an at the end almost equal reliability index $\beta$ of 5.2.

Instead of spending a great deal of time finding all failure modes of the system frame, this study investigates if, due to fire, one dominant failure mode and a number of critical sections can be characterized. This will be described in Chapter 3 for three different shape ratios of the single bay portal frame (height-to-span $H / L$ ) and three vertical load levels. The fire development follows the nominal standard fire curve from [8] and thermo-plastic analysis of all frames is done with the finite element method software (FEM) SAFIR® [9].

Then, additional exploration of the possibilities of the FBM as is proposed by [10] is done in Chapter 4, which focusses on the inclusion of the influence of temperature effects in the system of equation that describes the frame's structural behaviour. This is done to establish a more general method of study of steel portal frames subjected to fire, in agreement with the conditions set in [11].

In the FBM, the equations of equilibrium are formulated in the undeformed state and are not updated with deformation taking place. Since the interest of this paper goes to structures that survive a fire and stay in the elastic range, it is deemed acceptable. During the fire, thermal and mechanical material properties can be obtained in, among others, the following codified document [11]. For the post-fire evaluation, a statistical evaluation of the stress-strain characteristics of carbon and stainless steel grades being exposed to fire and then cooled down can be found in [12].

The most recent publication related to statistical evaluation of structures submitted to fire [13] provides information on the appropriate PDFs and coefficients of variation (V) describing the thermal loads. However, information on the PDFs of the hot gas temperature evolution and subsequently the steel temperature developed under natural fires for industrial buildings is scarce. One single-bay portal frame is used as a case-study to illustrate the methodology and obtained results. In Chapter 6 , the failure risk of the portal frame for some thermal scenarios is studied.

Post-fire conditions of the portal frame are discussed in Chapter 7. Partial (material) factors for steel structures that survived a fire, depending on the maximum reached temperature, are then proposed. The core question of this chapter is whether or not the proposed additional partial factors for material properties allow the assessment of a structure post-fire, guaranteeing a target reliability level of the existing real structure.

\section{FAILURE MODES AND CRITICAL SECTIONS IN CASE OF FIRE}

A single-bay portal frame as presented in Figure 1 (a) is considered. The basic variables and hypotheses of the problem are:

- The span between the centre lines of the columns $L$; 
- The height between the foundations and the centre line of the beam $H$;

- The geometrical properties of the cross-sections: the gross cross-section area $A$, the second moment of area $I_{z}$, and a time-dependent temperature increment $\Delta \theta$ (considered uniform over the crosssection) due to the fire. Indexes are $c L$ for the left column, $b$ for beam, and $c R$ for the right column on the figure (both columns can be different; however, this will not be the case in this paper);

- The mechanical properties are the same for all the profiles (same steel batch);

- Only in-plane displacements due to normal forces and bending moments are allowed and it is assumed that potential failures due to shear or instability will be eliminated by appropriate means;

- It is presumed that the global structural behaviour can be described in an elastic way and that imperfections will not have a major impact on the behaviour;

- The time history does not influence the mechanical behaviour of the portal frame; only the maximum temperature does;

- Columns and beam can have different properties and can be subjected to different maximum temperatures to simulate the effect of a local fire. However, the temperature is considered constant, per element along the whole length.
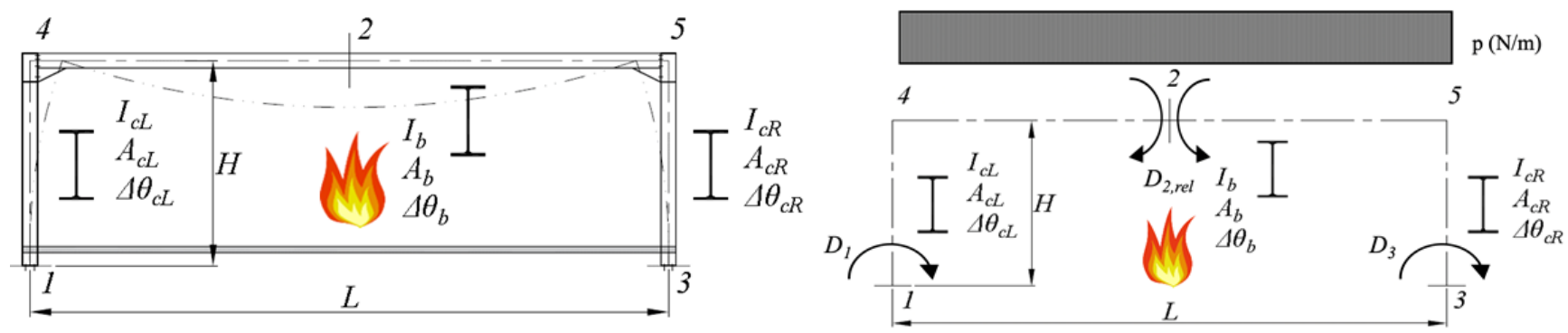

Figure 1. Typical single-bay portal frame of an industrial steel building (a) and a schematic version (b).

For rather simple structures, as the one presented in Figure 1 (a), the critical sections under ambient conditions can easily be based on the engineer's expertise, but can also be deduced from a FEM analysis until failure (subjected to a standard fire). However, in case of fire, the scenarios (the uniform or nonuniform application of heating in the compartment), $H / L$-ratio (shape factor) and load level investigated in this paper could lead to different failure modes as described in the following sub-sections.

All connections will be assumed to be perfectly rigid and, due to the presence of additional material, the thermal resistance will be higher than that of the connected elements. Standard European I-profile sections are used. Note that, in case of fire, the degree of indeterminacy can be higher than under ambient temperature. This is due to the possible and usual presence of concrete floor slabs that block the horizontal movements and rotations at the bottom level of the columns. Of course, this is only valid if the considered column passes through this concrete slab down to a lower level.

The failure modes depicted in Figure 2 are obtained by subjecting the presented portal frames to the mechanical load and a uniform compartment gas temperature (standard fire) that increases over the time and using the thermal-structural analysis software SAFIR ${ }^{\circledR}[9]$. Load levels in the figure are the ones that include the self-weight of the chosen profiles that satisfy for the gives ratios both service and ultimate limit states following the partial factor method according to [16] $(H=5$ or $10 \mathrm{~m}$ and $L=15$ or $20 \mathrm{~m})$. No wind load is considered acting on the portal frame as its effect was found neglectable, as also described in [7]. The failure is always initiated by the same mechanism as the one at ambient conditions. Plastic hinges initiate at nodes 4 and 5. When the cross-section at node 2 also starts to yield under catenary action, nodes 1 and 3 act as ends of a cantilever column and fail almost instantaneously which inevitably leads to global collapse of the system.
$H / L=0.25$
$H / L=0.33$
$H / L=0.67$ 

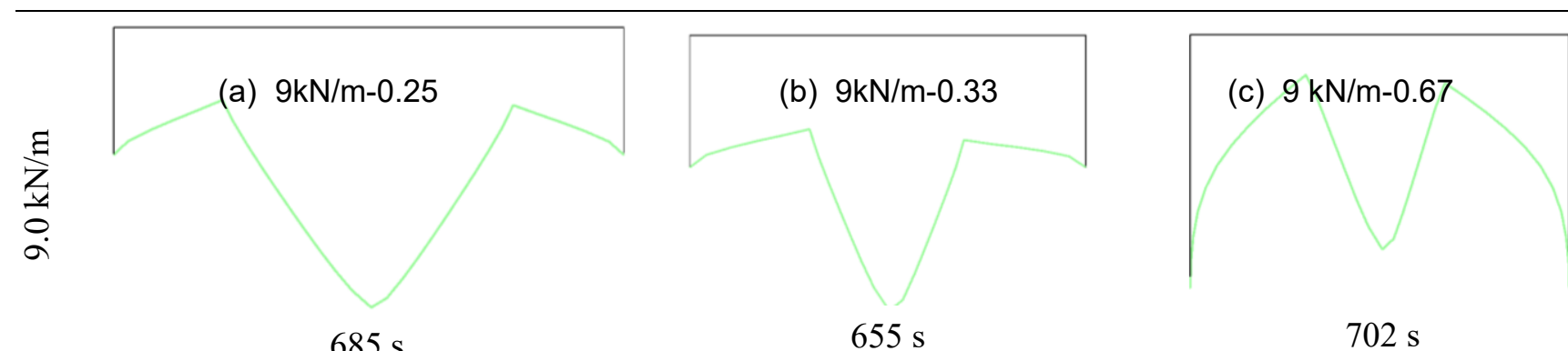

$685 \mathrm{~s}$

$655 \mathrm{~s}$

$702 \mathrm{~s}$

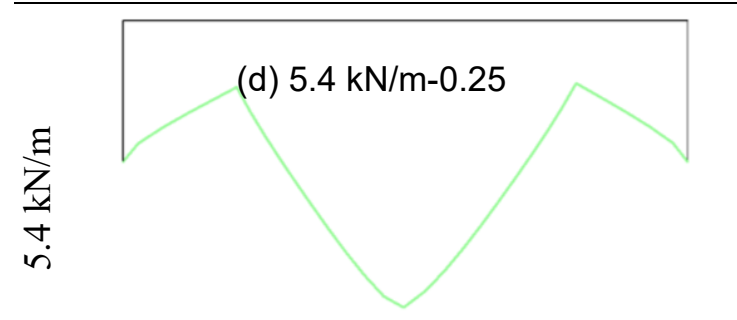

$735 \mathrm{~s}$

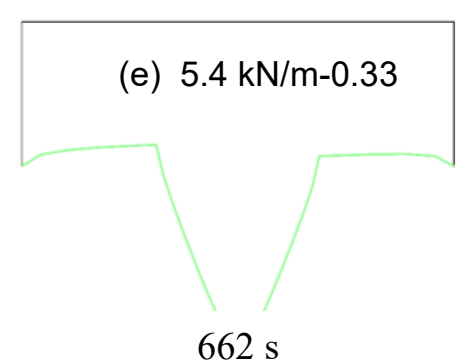

$662 \mathrm{~s}$ (f) $5.4 \mathrm{kN} / \mathrm{m}-0.67$

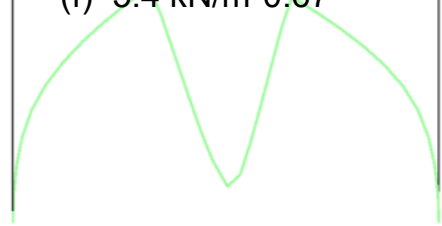

$754 \mathrm{~s}$

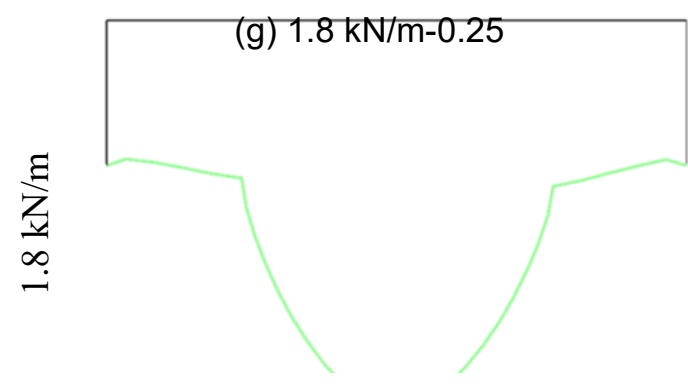

$2215 \mathrm{~s}$ (h) $1.8 \mathrm{kN} / \mathrm{m}-0.33$

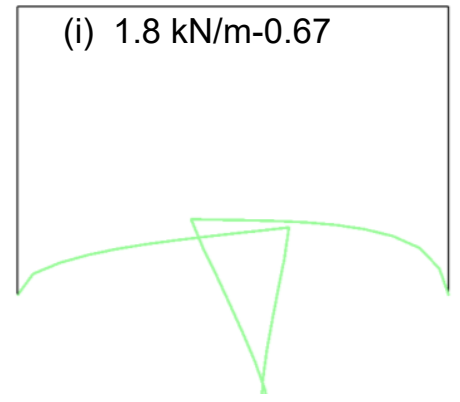

$769 \mathrm{~s}$

Figure 2. Failure modes and time of collapse due to uniform heating for several portal frames with $H / L$-ratio $0.25,0.33$, and 0.67 combined with 3 permanent load levels.

\section{FORCE-BASED METHOD FOR A SINGLE-BAY STEEL PORTAL FRAME}

The scope of the paper is limited to one type of structure i.e. a single-bay portal frame as shown in Figure 1 (b). The frame is composed of I-profile section members with their strong axis oriented in the plane. The unknown deformations (rotations) are located at the critical sections where failure is likely to occur (nodes 1 to 3). As previously mentioned, yielding is firstly initiated at nodes 4 and 5, which is the reason why the description of the mechanical behaviour is extended to 5 nodes (nodes 4 and 5 in addition to 1 to 3 , see Figure 1 (b)). The moments at these locations can be calculated based on equilibrium equations; see [10]. In the case of the investigated portal frames, the 3 moments $\left(\mathrm{M}_{1}, \mathrm{M}_{2}\right.$, and $\left.\mathrm{M}_{3}\right)$ at the critical nodes can then be obtained using the matrix in Eq. (1). In this case, the flexibility coefficients will depend on the temperature through Young's modulus temperature dependency:

$$
\left\{\begin{array}{l}
M_{1} \\
M_{2} \\
M_{3}
\end{array}\right\}=\left[\begin{array}{lll}
f_{11} & f_{12} & f_{13} \\
f_{21} & f_{22} & f_{23} \\
f_{31} & f_{32} & f_{33}
\end{array}\right]^{-1}\left\{\begin{array}{l}
-D_{10}-D_{1, t} \\
-D_{20}-D_{2, t} \\
-D_{30}-D_{3, t}
\end{array}\right\}
$$

The moments should then be compared to the bending moment capacity of the corresponding cross-section to verify if the system has reached failure, i.e. a unity check as provided in [16] is used for each node, disregarding the contribution of normal and shear forces, resulting in a utilisation ratio $\eta_{j}$ for each node $\mathrm{j}$ as in Eq. (2). 


$$
\eta_{j}=\frac{E_{j}}{R_{j}}=\frac{M_{E d, j}}{M_{R d, j}} \leq 1
$$

For Class 1 sections with a normal force lower than $25 \%$ of the plastic cross-sectional capacity as well as $50 \%$ of the web capacity [16]:

- $M_{E d, j}$ is the considered internal moment as a result of the applied external factored loads;

- $M_{R d, j}$ is the temperature-dependent design resting moment equal to the product of the section modulus by the yield strength for steel members.

\section{STATISTICAL DATA}

Statistical data required for reliability analyses are needed at 3 levels in ambient conditions: the mechanical load, the material and the geometrical properties. This kind of information can be found in $[18,19,20,13]$. Natural fires will be modelled with an adjusted parametric fire model based on [8]. This will be processed for 3 typical design fires as described in [15] for industrial buildings. Based on the developed temperaturetime curves, the steel temperature of unprotected elements is then calculated based on [11]. The coupling with the mechanical model using the FBM for different scenarios and the evaluation of the reliability level will be the topics of Chapter 6 .

\subsection{Reference statistical data to describe the thermal action}

The structural response of a system will be highly dependent on the thermal action. A temperature-time curve can be evaluated based on the building characteristics such as wall thermal effusivity (with values for different materials mostly ranging between 100 and $2200 \mathrm{~J} / \mathrm{m}^{2} \mathrm{~s}^{1 / 2} \mathrm{~K}$ ), opening factor, geometrical dimensions of the portal frame and as well as on the fire load. Those are characterized by distributions with specific averages and standard deviations as provided in Table 1 [5].

Table 1. PDFs according to [5].

\begin{tabular}{|c|c|c|c|}
\hline Variable X & Distribution & $\begin{array}{l}\text { Averages as fractile of the } \\
\text { characteristic value } X_{k}\end{array}$ & Coefficient of variation $V_{X}$ \\
\hline \multirow{2}{*}{$\begin{array}{l}\text { Thermal } \\
\text { characteristics } \\
\text { of a wall } \boldsymbol{b}= \\
\sqrt{\boldsymbol{\rho} \boldsymbol{c} \lambda}\end{array}$} & Beta (B) & 0.50 & 0.05 \\
\hline & Determined (D) & 0.50 & 0 \\
\hline \multirow{2}{*}{$\begin{array}{l}\text { Opening } \\
\text { factor } \\
\qquad \boldsymbol{O}=\frac{\boldsymbol{A}_{v} \sqrt{\boldsymbol{h}_{e q}}}{\boldsymbol{A}_{\boldsymbol{t}}}\end{array}$} & Lognormal (LN) & 0.50 & 0.1 \\
\hline & $\mathrm{D}$ & 0.50 & 0 \\
\hline \multirow{2}{*}{$\begin{array}{l}\text { Geometrical } \\
\text { dimensions }\end{array}$} & Normal (N) & $0.50^{*}$ & $0.005 \rightarrow 0.03$ \\
\hline & $\mathrm{D}$ & & 0 \\
\hline \multirow[t]{2}{*}{ Fire load $\mathrm{q}_{\mathrm{f}}$} & Gumbel (maxima) & 0.80 & 0.3 \\
\hline & B & & $\rightarrow 0.10$ \\
\hline
\end{tabular}

*This value comes from the reference document but is deemed to be erroneous

Most material properties follow a lognormal (LN) distribution however, in [5] it is recommended to use a beta (B) distribution or a determined parameter. With the rather low $\mathrm{V}$ of 0.05 , the difference between the $\mathrm{B}$ and $\mathrm{LN}$ distribution is insignificant, which is why a $\mathrm{LN}$ distribution is presently selected. The distribution is applied on the thermal effusivity $b\left(\mathrm{~J} / \mathrm{m}^{2} \mathrm{~s}^{1 / 2} \mathrm{~K}\right)$ which is the square root of the product of the density $\rho$ $\left(\mathrm{kg} / \mathrm{m}^{3}\right)$, the thermal capacity $c(\mathrm{~J} / \mathrm{kgK})$, and the conductivity $\lambda(\mathrm{W} / \mathrm{mK})$. All other material constants will be assumed to be determined parameters. 
A lognormal (LN) distribution is proposed for the opening factor $O$, composed of the product of the vertical openings $A_{v}\left(\mathrm{~m}^{2}\right)$, the square root of the surface weighted height $h_{e q}(\mathrm{~m})$ of the openings divided by the total surface of the surroundings $A_{t}\left(\mathrm{~m}^{2}\right)$ openings included.

The geometrical dimensions of the compartment are the width $(B)$, length $(L)$, and height $(H)$ of a compartment expressed in $(\mathrm{m})$. The range of possible V's for the geometrical overall system's dimensions is relatively high. In [21], a value of 0.022 was derived and will also be used here for sake of consistency. It should be noted that the recommended value of 0.5 as average fractile from [5] is probably a typing error and should be 1.0 .

For the thermal load, Annex E of [8] refers to the Gumbel distribution, see Table E.4, with the fire load densities related to the floor area $q_{f}$. The same distribution will be applied to the fire load density $q_{t}$ related to the total surface of the enclosure.

\subsection{Temperature-time relationships}

The temperature-time relationship of the gas $\left(\theta_{g}\right)$ will generate a thermal action on the surface of the structural members. With this information, the net heat flux can be determined by taking the heat transfer by convection and radiation into account [8]. For a four-sided heated unprotected profile, the equivalent uniform steel temperature can be calculated according to [11] as well as its mechanical response assessed. The coupling process between the thermal action calculation and mechanical response evaluation will be executed in time steps of 60 seconds.

Two types of models can be distinguished to set up the temperature-time relationship [18]. The first one is based on energy, mass balance equations, and gas properties (chemistry), while the second types of model are based on simplified semi-empirical equations. The last ones have the advantage that they can be worked out in an easy manner perfectly suited for multiple analyses and deliver still accurate results [22]. The Eurocode parametric-time (PF) curve from Annexe A [8] is well-suited for this purpose, see [6]. However, for reliability analyses, preference is given to an analytical continuous function [5] capable of estimating the maximum temperature based on the fire duration [25]. In [23] it is suggested to use the adjusted parametric fire (APF) instead. A brief summary of the formulation and its adjustments, including those proposed in [23] leading to a continuous and more accurate curve is given in Table 2. Considering the ratio $\theta_{\bmod } / \theta_{\text {test }}$ of the maximum calculated temperature of the model $\left(\theta_{\bmod }\right)$ to the test temperature $\left(\theta_{\text {test }}\right)$, the best fit is obtained by a unique numerical parameter equalling $0.14 \cdot 10^{-3}$.

Table 2. Successive steps needed for the adjusted parametric fire.

\begin{tabular}{|c|c|}
\hline Step & APF [23] \\
\hline $\begin{array}{l}\text { Thermal characteristics of } \\
\text { compartments at } 20^{\circ} \mathrm{C}\end{array}$ & $b=\sqrt{\rho c \lambda}$ and $b_{\text {comp }}=\frac{\sum\left(b_{j} A_{j}\right)}{\left(A_{t}-A_{v}\right)}$ \\
\hline Opening factor & $O=\frac{A_{v} \sqrt{h_{e q}}}{A_{t}}$ \\
\hline Fire load & $q_{t}=q_{f} \frac{A_{f}}{A_{t}}$ \\
\hline $\begin{array}{l}\text { Severity factor } \Gamma(>1= \\
\text { worse than standard fire })\end{array}$ & $\Gamma=\left(\frac{0 / 0.04}{b / 1160}\right)^{2}$ \\
\hline $\begin{array}{l}\text { Shortest duration time } t_{\lim } \\
\text { (hours) }\end{array}$ & $t_{\text {lim }}=25 / 60$ for slow, 20/60 for medium, and $15 / 60$ for fast growth rate \\
\hline $\begin{array}{l}\text { Duration heating phase } \\
t_{\max } \text { (hours) }\end{array}$ & $t_{\max }=0.14 \cdot 10^{-3} \frac{q_{t, d}}{O}$ \\
\hline $\begin{array}{l}\text { If } t_{\max }>t_{\lim }(\text { ventilation- } \\
\text { controlled })\end{array}$ & $\begin{array}{c}\theta_{g, \text { heating }}=20+1325\left(1-0.324 e^{-0.2 t^{*}}-0.204 e^{-1.7 t^{*}}-0.472 e^{-19 t^{*}}\right) \\
\text { With } t^{*}=\Gamma \cdot t \text { until } t_{\max }^{*}=\Gamma \cdot t_{\max }\end{array}$ \\
\hline
\end{tabular}




\begin{tabular}{|c|c|}
\hline $\boldsymbol{\theta}_{g, \text { cooling }} \geq 20^{\circ} \mathrm{C}$ & $\begin{array}{c}\theta_{g, \text { cooling }}=\theta_{\max }-625\left(t^{*}-t_{\max }^{*}\right) \text { for } t_{\max }^{*}<0.5 \\
\theta_{g, \text { cooling }}=\theta_{\max }-250\left(3-t_{\max }^{*}\right)\left(t^{*}-t_{\max }^{*}\right) \text { for } 0.5<t_{\max }^{*}<2.0 \\
\theta_{g, \text { cooling }}=\theta_{\max }-250\left(t^{*}-t_{\max }^{*}\right) \text { for } 2.0<t_{\max }^{*}\end{array}$ \\
\hline $\begin{array}{l}\text { If } \mathrm{t}_{\max } \leq \mathrm{t}_{\text {lim }} \text { (fuel- } \\
\text { controlled) }\end{array}$ & $\begin{aligned} O_{\text {lim }} & =0.14 \cdot 10^{-3} \frac{q_{t, d}}{t_{\text {lim }}} \\
\Gamma_{\text {lim }} & =\left(\frac{O_{\text {lim }} / 0.04}{b / 1160}\right)^{2}\end{aligned}$ \\
\hline $\begin{array}{l}\text { Correction to } \Gamma_{\text {lim }} \text { for large } \\
\text { openings in a fuel- } \\
\text { controlled situation }\end{array}$ & $\begin{array}{c}\text { If } \mathrm{O}>0.04 \mathrm{~m}^{1 / 2} \text { and } \mathrm{q}_{\mathrm{t}}<75 \mathrm{~mJ} / \mathrm{m}^{2} \text { and } \mathrm{b}<1160 \mathrm{~J} / \mathrm{m}^{2} \mathrm{~s}^{1 / 2} \mathrm{~K} \\
k=1+\left(\frac{O-0.04}{0.04}\right)\left(\frac{q_{t}-75}{75}\right)\left(\frac{1160-b}{1160}\right) \\
\theta_{g, \text { heating }}=20+1325\left(1-0.324 e^{\left.-0.2 t^{*}-0.204 e^{-1.7 t^{*}}-0.472 e^{-19 t^{*}}\right)}\right. \\
\text { With } t^{*}=\Gamma_{\text {lim }} \cdot t \text { until } t_{\text {max }}^{*}=\Gamma_{\text {lim }} \cdot t_{\text {lim }} \\
\theta_{g, \text { cooling }}=\theta_{\text {max }}-625\left(t^{*}-t_{\text {lim }}^{*}\right) \text { for } t_{\text {max }}^{*}<0.5 \\
\theta_{\text {g,cooling }}=\theta_{\text {max }}-250\left(3-t_{\text {max }}^{*}\right)\left(t^{*}-t_{\text {lim }}^{*}\right) \text { for } 0.5<t_{\text {max }}^{*}<2.0 \\
\theta_{\text {g,cooling }}=\theta_{\text {max }}-250\left(t^{*}-t_{\text {lim }}^{*}\right) \text { for } 2.0<t_{\text {max }}^{*}\end{array}$ \\
\hline
\end{tabular}

One of the limitations of the parametric fire model concerns the compartment geometry, the floor area of which should be limited to $500 \mathrm{~m}^{2}$ and ceiling height to $4 \mathrm{~m}$ [8]. Nevertheless, scaling the parametric fire can be imagined as long as the ratio between the vertical openings and the total surface of the compartment, the equivalent height, the fire load versus the total surface as well as the thermal properties are kept constant.

The Belgian regulation [15] provides the dimension of a typical industrial building i.e. $60 \mathrm{~m}$ long, $12 \mathrm{~m}$ high, and $\mathrm{L} / \mathrm{B}=3$ with the following building characteristics: gates of $5 \times 5 \mathrm{~m}^{2}$ combined with doors of $0.95 \times 2.2 \mathrm{~m}^{2}$ as depicted in Fout! Verwijzingsbron niet gevonden. as well as square skylights of $1.2 \mathrm{~m}$ high in the roof, see Fout! Verwijzingsbron niet gevonden., which leads to an opening factor $O$ of 0.15 and an equivalent height $h_{e q}$ of $3.35 \mathrm{~m}$. All fires appear to be fuel-controlled with $t_{\max }=20$ min due to a relatively high opening factor $O$. A summary of the fire load density as well as the gas and steel temperature can be found in Table 3 .

Table 3. Gas and steel temperatures for a typical portal frame steel building

\begin{tabular}{lccc}
\hline Temperature $\left({ }^{\circ} \mathrm{C}\right)$ & Class $\mathrm{A}\left(225 \mathrm{~mJ} / \mathrm{m}^{2}\right)$ & Class B $\left(625 \mathrm{~mJ} / \mathrm{m}^{2}\right)$ & Class $\mathrm{C}\left(1250 \mathrm{~mJ} / \mathrm{m}^{2}\right)$ \\
\hline$\theta_{\mathrm{g}}$ with standard values & 748 & 1035 & 1246 \\
$\theta_{\mathrm{a}}$ with standard values & 711 & 1032 & 1246 \\
\hline$\theta_{\mathrm{g}}, b_{\text {comp }}=1742 \mathrm{~J} / \mathrm{m}^{2} \mathrm{~s}^{1 / 2} \mathrm{~K}$ & 492 & 838 & 1045 \\
$\theta_{\mathrm{a}}, b_{\text {comp }}=1742 \mathrm{~J} / \mathrm{m}^{2} \mathrm{~s}^{1 / 2} \mathrm{~K}$ & 401 & 800 & 1042 \\
\hline$\theta_{\mathrm{g}}, O=0.05 \mathrm{~m}^{1 / 2}$ & 748 & 979 & 1081 \\
$\theta_{\mathrm{a}}, O=0.05 \mathrm{~m}^{1 / 2}$ & 713 & 974 & 1080 \\
\hline
\end{tabular}

Firstly, the gas and steel temperature under fuel-controlled conditions are high, and so is the failure risk. Secondly, for the Class C fire load, both the gas and steel temperatures reach $1200^{\circ} \mathrm{C}$ i.e. the maximum temperature used in [11]. To illustrate the capabilities of the APF, Table 3 also shows the values with an almost double effusivity $b$ and one third of the opening factor $O$, where all other properties are kept constant.

\section{EVOLUTION OF THE RELIABILITY INDEX DURING A FIRE}

It was shown that the FBM as described in [10] is a good tool for comparative reliability-based assessment of portal frame and approximates well the results of the comprehensive probabilistic analysis from [7]. By 
including the temperature-dependent deformations in the matrix equation (Eq. (1)) of Chapter 4, the method enable to capture the effect of uniform temperature effects (along a member). The influence of heating on the reliability of a single-bay portal frame can be achieved by coupling the outputs of the simulations presented in section Fout! Verwijzingsbron niet gevonden. to the FBM analysis.

Out of the portal frames proposed in Chapter 3, the frame (c) is here chosen as case-study. Note that the results of sections 5.2 and 5.3 are independent of the building shape. They vary with the parameters of the fire i.e. the opening factor $O$, equivalent height $h_{e q}$ and effusivity of the compartment $b_{c o m p}$. The most important statistical data are summarized in Table 4. Determined values are used for other parameters.

Table 4. Summary of statistical data for thermal and structural analysis of the chosen portal frame (c).

\begin{tabular}{|c|c|c|c|c|c|c|}
\hline Subject & Property & Unit & Characteristic & Distribution & Mean $\mu$ & V \\
\hline \multirow{3}{*}{$\begin{array}{l}\text { Resistance } \\
\text { beam IPE360 }\end{array}$} & $A, W_{p l}$ & $\mathrm{~m}^{3}$ & $1019 \cdot 10^{-6}$ & $\mathrm{~N}$ & $804.3 \cdot 10^{-6}$ & 0.02 \\
\hline & $f_{y}$ & $\mathrm{~N} / \mathrm{m}^{2}$ & $235 \cdot 10^{6}$ & LN & $327 \cdot 10^{6}$ & 0.08 \\
\hline & $E$ & $\mathrm{~N} / \mathrm{m}^{2}$ & $210 \cdot 10^{9}$ & $\mathrm{~N}$ & $210 \cdot 10^{9}$ & 0.001 \\
\hline \multirow{3}{*}{$\begin{array}{l}\text { Resistance } \\
\text { column IPE400 }\end{array}$} & $A, W_{p l}$ & $\mathrm{~m}^{3}$ & $1307 \cdot 10^{-6}$ & $\mathrm{~N}$ & $804.3 \cdot 10^{-6}$ & 0.02 \\
\hline & & $\mathrm{N} / \mathrm{m}^{2}$ & $235 \cdot 10^{6}$ & $\mathrm{LN}$ & $327 \cdot 10^{6}$ & 0.08 \\
\hline & E & $\mathrm{N} / \mathrm{m}^{2}$ & $210 \cdot 10^{9}$ & $\mathrm{~N}$ & $210 \cdot 10^{9}$ & 0.001 \\
\hline $\begin{array}{l}\text { Dimensions, } \\
\text { fire }\end{array}$ & $L$ and $H$ & $\mathrm{~m}$ & 15 and 10 & $\mathrm{~N}$ & $H$ and $L$ & 0.022 \\
\hline mechanical & $L$ and $H$ & $\mathrm{~m}$ & 15 and 10 & $\mathrm{~N}$ & $0.95 H$ and $L$ & 0.022 \\
\hline \multirow[t]{2}{*}{ Load } & $S W$ & $\mathrm{~N} / \mathrm{m}$ & 568 & $\mathrm{~N}$ & 568 & 0.02 \\
\hline & $D L$ & $\mathrm{~N} / \mathrm{m}$ & 9000 & $\mathrm{~N}$ & 9000 & 0.10 \\
\hline \multirow{4}{*}{ Thermal } & $b_{\text {comp }}$ & $\mathrm{J} / \mathrm{m}^{2} \mathrm{~s}^{1 / 2} \mathrm{~K}$ & 902 & $\mathrm{LN}$ & 902 & 0.05 \\
\hline & $O$ & $\mathrm{~m}^{1 / 2}$ & 0.15 & $\mathrm{LN}$ & 0.15 & 0.10 \\
\hline & $L, B$ and $H$ & $\mathrm{~m}$ & $\mathrm{~L}, \mathrm{~B}$, and $\mathrm{H}$ & $\mathrm{N}$ & $L, B$, and $H$ & 0.022 \\
\hline & $q t$ & $\mathrm{MJ} / \mathrm{m}^{2}$ & $1.22 \times A, B, C$ & GU+ & $\mathrm{A}, \mathrm{B}$, or $\mathrm{C}$ & 0.30 \\
\hline
\end{tabular}

Using the data above, a reliability index $\beta$ higher than 7.9 was found in ambient conditions $\left(20^{\circ} \mathrm{C}\right)$. The different fire Classes highlighted in Table 3 do correspond to another use of the building but, since the steel temperatures rises (from Class A to Class C), this can also be seen as a developing fire in a compartment. All other parameters being kept constant, the calculated $\beta$ is evaluating from bigger as 7.9 at $20^{\circ} \mathrm{C}$ to respectively $1.64,-2.52,-2.31$ and -2.04 for temperatures of $395,704,1028$ and $1242{ }^{\circ} \mathrm{C}$. Based on those values it follows that the probability of system's failure $P_{f}$ in the case of a compartment fire is only acceptable at relatively low temperatures $\left(395^{\circ} \mathrm{C}\right)$ when the effusivity equals $1742 \mathrm{~J} / \mathrm{m}^{2} \mathrm{~s} \mathrm{~s}^{1 / 2} \mathrm{~K}$. In this case, a failure risk of $50 \%$ can be (backward-) calculated for a steel temperature of about $520{ }^{\circ} \mathrm{C}$ only.

\section{POST-FIRE RELIABILITY OF SINGLE-BAY PORTAL STEEL FRAMES}

Where the evolution of the reliability level during a fire can be seen as an application example, the real added value of the method is the post-fire reliability assessment of structures. Based on the evaluation of 718 tests collected from 19 references, reliability-based, post-fire steel material properties and safety factors are calculated in [12]. The retention factor versus temperature can be found in Table 5, see [12]. They can be used in the assessment of existing steel structures that suffered and survived a fire. The data is used to derive retention factors for each of the significant and characteristic material properties and adjusted safety factors (for post-fire assessment of structures) based on the detailed analysis. Both factors depend on the maximum temperature to which the steel is exposed. It is shown that, for traditional strength steel, the impact of fire on the post-fire mechanical properties remains reasonable up to 
temperatures approaching $1000^{\circ} \mathrm{C}$. It is also proposed that the safety factor $\gamma_{M 0, p o s t, \theta}$ is increased to 1.15 starting from heating above $650^{\circ} \mathrm{C}$ for traditional strength carbon steel, with a modified reliability level $\beta$ of 3.3 proposed for the assessment of existing structures. The work is based on a statistical evaluation of test data without dealing with the behaviour of a part of the structure.

Here, validation of the suggested additional partial factors will be done for the three load fire Class i.e. for averaged maximum steel temperatures of 704,1028 , and $1242^{\circ} \mathrm{C}$ as calculated in Chapter 3 on the nine portal frames i.e. with three different shape ratios $H / L$ ranging from 0.25 to 0.67 . And thus, three load ratios (superimposed dead load from 1.8 until $9 \mathrm{kN} / \mathrm{m}$ ) will be considered. All factors and their appropriate PDFs can be found in Table 4. In this evaluation, only permanent loads will be considered $(\mathrm{V}=0.10)$. Because the material safety factors for carbon steel is equal to 1.0, the effect on the reliability level can easily be considered by using an additional safety factor, where appropriate. Each random series of simulation is then repeated five times to increase accuracy. In total, this results in 9 portal frames with 3 fire loads, and 1000 repeated 5 times, i.e. 135000 simulations.

Table 5. Proposed simplified retention factors suitable for verification of normal structural steel (NSS).

\begin{tabular}{|c|c|c|c|c|c|c|c|}
\hline Property & $R_{y, \theta}$ & & & $R_{E, \theta}$ & & \multirow[b]{4}{*}{$\underset{\text { Temperature }\left({ }^{\circ} \mathrm{C}\right)}{\longrightarrow}$} & \multirow[b]{3}{*}{$\begin{array}{l}\mathrm{R}_{\mathrm{E}, \theta} \\
\uparrow\end{array}$} \\
\hline$\theta\left({ }^{\circ} \mathrm{C}\right) / R_{\theta}$ & $\theta_{A}$ & $\theta_{B}$ & $\theta_{C}$ & $\theta_{A}$ & $\theta_{B}$ & & \\
\hline All & $\begin{array}{l}400 / \\
1.00\end{array}$ & $\begin{array}{l}750 / \\
0.40\end{array}$ & $\begin{array}{l}1200 / \\
0.13\end{array}$ & $\begin{array}{l}700 / \\
1.00\end{array}$ & $\begin{array}{l}1200 / \\
0.65\end{array}$ & & \\
\hline NSS & $\begin{array}{l}600 / \\
1.00\end{array}$ & $\begin{array}{l}750 / \\
0.75\end{array}$ & $\begin{array}{l}1000 / \\
0.62\end{array}$ & $\begin{array}{l}800 / \\
1.00\end{array}$ & $\begin{array}{c}1000 / \\
0.90\end{array}$ & & $\underset{\text { Temperature }\left({ }^{\circ} \mathrm{C}\right)}{\longrightarrow}$ \\
\hline
\end{tabular}

Furthermore, for the reinstatement of (existing) buildings, the reliability level can be decreased to find an acceptable level taking into account economical and societal aspects [27], [28]. In accordance with ISO 2394 [29], and as is proposed in [12]. a value of 3.3 for the post-fire reliability index $\beta$ is proposed.

\subsection{Compartment fire}

A compartment fire was firstly investigated which is generally considered to be the most severe situation [22] for an industrial building and, due to the floor area, this scenario is generally assumed to be very unlikely to occur. In Figure 3 it is shown that only for low fire loads (Class A) i.e. after being submitted to relatively low temperatures the post-fire reliability level remains above an acceptable minimum target value.

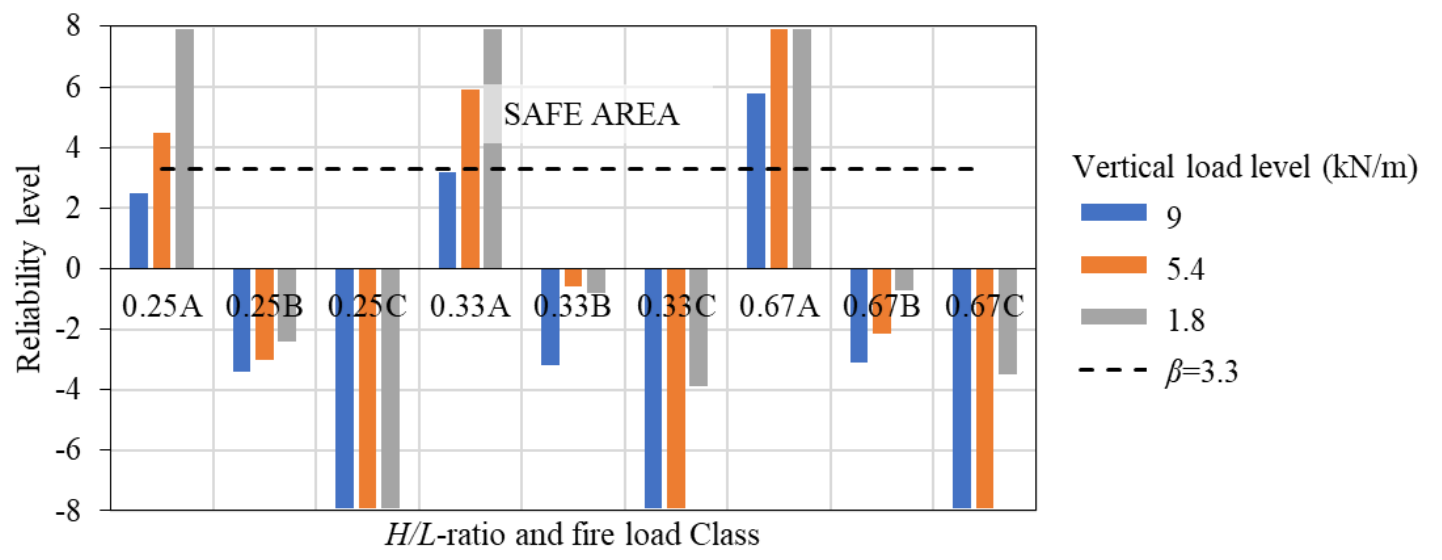

Figure 3 Reliability level in function of the $H / L$-ratio for different fire and vertical loads due to uniform heating.

\subsection{Local fire against a column}

The same analysis is here done on a portal frame where only one column is submitted to a local fire. The reliability level only slightly increases when only a single column is engulfed in the fire, however leading to the same conclusions. Figure 4 compares the failure times for the case of a fire next to the left column. It is seen that the difference in reliability levels is not as pronounced as the difference in collapse time. 


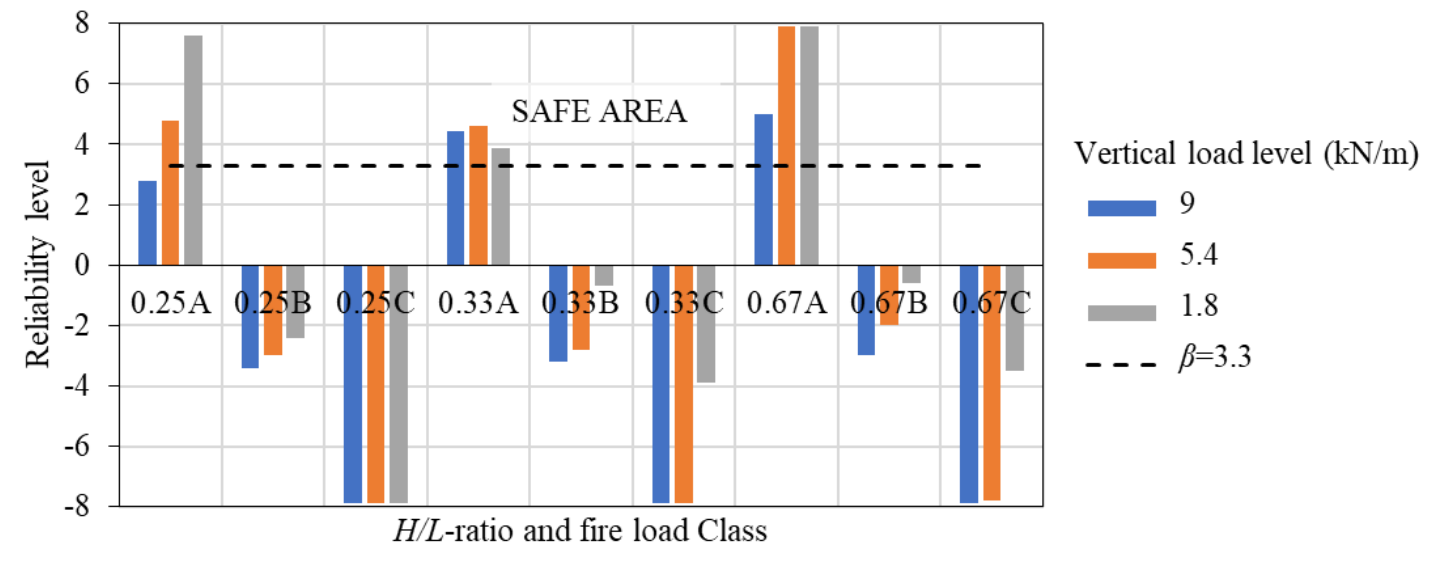

Figure 4 Reliability level in function of the $H / L$-ratio for different vertical loads due to local column heating (left column).

It is clear that the assumption made by [22] that a compartment fire is the most severe scenario can now be confirmed based on the outcomes of this reliability assessment, the differences are almost negligible.

\subsection{Beam in the hot smoke layer}

A common assessment question is what should be done with the structures when only the beam of the frame was engulfed in the hot smoke layer. This can happen in case of a local fire but, usually more often, in combination with a severe fire during which part of the structure collapsed and the interest lies in whether the remaining part can still be re-used in a reliable way. From Figure 5, it can be seen that if the beam does not fail during the fire, the reliability level can be guaranteed.

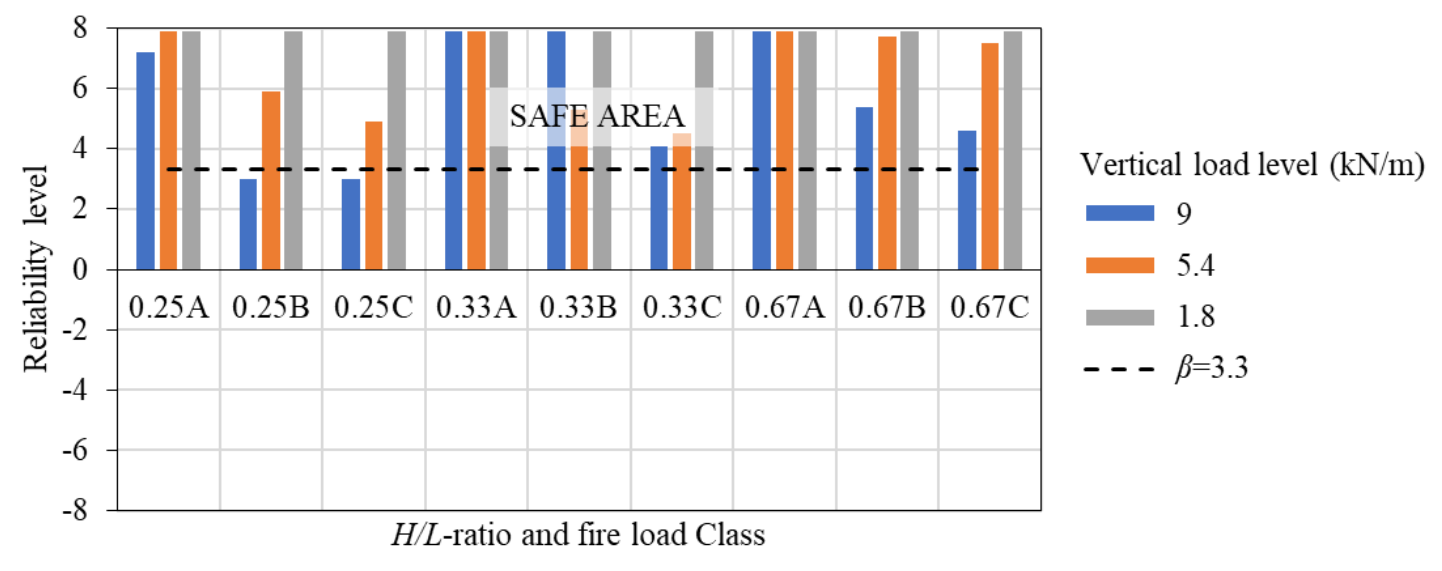

Figure 5 Reliability level in function of the $H / L$-ratio for different vertical loads and a beam in the hot smoke layer.

Only the combination of big span with high dead load, and a moderate to severe fire (Class B and C) could lead to a too low reliability index. This conclusion seems to be confirmed by several observations from practical cases investigated by the authors in the past years. References can be found in [25] of recent reinstated structures.

\subsection{Reliability evaluation}

In [12], a material additional safety factor of 1.15 was proposed to assess the post-fire resistance of structures having reached $650^{\circ} \mathrm{C}$, in order to deal with the increased uncertainty level on the material properties. It is worth underlining that material reduction factors are only needed once heated above $1000^{\circ} \mathrm{C}$ i.e. most probably a point at which the structure has collapsed. It is worth recalling that only permanent loads are applied on the portal frame and that the (ambient temperature) material safety factor is equal to one which results in a clear link between the utilization ratio $\eta$ (including the additional post-fire safety factor) and the reliability level (see Eqs. (3) and (4)). 


$$
\begin{gathered}
\eta=\frac{E_{d}}{R_{d, p o s t}}=\frac{\gamma_{G} G}{R /\left(\gamma_{M} \gamma_{M 0, \theta, p o s t}\right)}=\frac{\gamma_{M 0, \theta, p o s t} \gamma_{G} G}{R} \\
\gamma_{G}=\gamma_{E d, G} \cdot \gamma_{g}=\gamma_{E d, G} \cdot \frac{\mu_{G}\left[1-\alpha_{E} \beta V_{G}\right]}{\mu_{G}\left[1+k \cdot V_{G}\right]} \approx 1.07 \cdot\left[1-\alpha_{E} \beta V_{G}\right]
\end{gathered}
$$

Those are based on the recommendations of [30], with a model uncertainty factor $\gamma_{E d, G}$ of 1.07 for an unfavourable action, $k=0$, which is commonly assumed for permanent actions, $\alpha_{E}$ is the sensitivity factor $(-0.7[31])$, and $V_{G}$ is the standard deviation for the permanent loads.

It is seen that where Classes $\mathrm{B}$ and $\mathrm{C}$ reach $1000^{\circ} \mathrm{C}\left(1028^{\circ} \mathrm{C}\right.$ and $1242^{\circ} \mathrm{C}$ respectively) and thus do not reasonably survive the fire $\left(\beta<0\right.$ or $\left.P_{f}<0.5\right)$; see Figure 3 . However, Class A (with effusivity up to $1742 \mathrm{~J} / \mathrm{m}^{2} \mathrm{~s}^{1 / 2} \mathrm{~K}$ ) works perfectly well up to $704^{\circ} \mathrm{C}$.

For a Consequence Class 2 building, the safety factor on permanent action is equal to 1.35 [31], hence the product $\alpha_{\mathrm{E}} \cdot \beta \cdot V_{G}$ is equal to -0.26 . In post-fire conditions, this will therefore become -0.45 since an additional post-fire partial factor of 1.15 is used. Neither the sensitivity factor nor the standard deviation on permanent actions will be changed. Hence, this can only be explained by an increased reliability level $\beta$ which is multiplied by a factor $0.45 / 0.26=1.72$. The lowest value for a Class A fire from Figure 3 to Fout! Verwijzingsbron niet gevonden. is 2.5 , and so will be increased up to $1.72 \cdot 2.5=4.3$, i.e. there is still some resistance reserve. This reserve is of prime importance to guarantee an adequate reliability level at higher exposure up to $1000^{\circ} \mathrm{C}$. By the application of the proposed methodology, it is therefore proven that the adjusted partial factor method delivers safe results for single-bay portal frames.

\section{CONCLUSIONS}

By comparing the results of numerical analysis (SAFIR ${ }^{\circledR}[9]$ ) to analytical solutions it was shown that reasonable evaluations of the structural failure modes of single-bay portal frames submitted to high temperatures can be achieved. The methodology based on the assessment of critical sections can be extended to structures subjected to fire as well as to assess them in post-fire situation.

To facilitate the reliability analysis, the adjusted parametric fire as proposed by [23] is well-suited to be coupled to the developed FBM equations. By including the time-dependent formulation of the heat transfer, it is possible to develop a methodology for a full probabilistic (analytical-) analysis of a single-bay portal frame during a fire and in post-fire conditions.

An evaluation of the reliability of single-bay portal frames is then performed for several fire load levels (during and after the fire) and 3 different length-to-height ratios. It was found that the reliability of structures during a fire is rapidly decreasing. Only buildings with a high thermal inertia (high effusivity) do deliver an acceptable level of safety if they remain under $400^{\circ} \mathrm{C}$. Otherwise, entering the building should be prohibited. Starting from $520^{\circ} \mathrm{C}$ the failure and survival probability are equal.

Post-fire reliability calculations are then performed for a compartment fire as well as for various local fire scenarios such as a heated column, a column and a beam or only the beam engulfed in a hot smoke layer. When the beam only is engulfed in the fire, all the studied geometries can survive the fire (i.e. keeping reasonable reliability level). However, it is only if the temperature remains below an acceptable level (about $700^{\circ} \mathrm{C}$ i.e. for Class A fire) that the scenario involving heating of the beam provides satisfying reliability.

Finally, it is shown that the procedure developed in [12] for the post-fire verification of remaining structural parts having been submitted to fire and cooled down delivers safe results, encouraging the reinstatement of structures over their dismantling.

\section{REFERENCES}

[1] M. H. Faber, „Risk assessment in engineering - Principles, system representation and risk criteria,” JCSS, Zürich, 2008. 
[2] H. Gulvanessian, J.-A. Calgaro en M. Holicky, Designers' guide to Eurocode: Basis of structural design EN 1990, 2nd red., London: ICE Publishing, 2012.

[3] K. Sidibé, F. Duprat, M. Pinglot en B. Bourret, „Fire safety of reinforced concrete columns,” ACI-journal, 2000.

[4] R. Van Coile, E. Annerel, R. Caspeele en L. Taerwe, „Full-probabilitic analysis of concrete beams during fire,” Journal of structural fire engineering, vol. 4, pp. 165-174, 2013.

[5] Handbook 5, Implementation of Eurocodes: Handbook 5 - Design of buildings for the fire situation, Luxembourg: European Commission, Joint Research Centre, CZ/02/B/F/PP-134007, Leonardo Da Vinci Pilot Project, 2005.

[6] Q. Guo en A. E. Jeffers, „Finit-element reliability analysis of structures subjected to fire,” Journal of structural engineering, pp. 1-11, 2014.

[7] EUR 21695, „Probabilitic quantification of safety of a steel structure highlighting the potential of steel versus other materials," European Comission, Luxembourg, 2005.

[8] EN 1991-1-2, Actions on structures - Part 1-2: General actions - Actions on structures exposed to fire, Brussels: CEN, 2002.

[9] J. Franssen en T. Gernay, „Modelling structures in fire with SAFIR,” Journal of Structural Fire Engineering, vol. 8, nr. (3), pp. 300-323, 2017.

[10] T. Molkens en B. Rossi, „Determination of the structural behaviour of single storey steel buildings in case of fire by a simplified force-based method," in IFireSS, Ottawa, CA, 2019.

[11] EN 1993-1-2, Design of steel structures - Part 1-2: General rules - Structural fire design, Brussels: CEN, 2004.

[12] T. Molkens, K. A. Cashell en B. Rossi, „Post-fire mechanical properties of carbon steel and safety factors for the reinstatement of steel structures," Engineering structures, p. Under review, 2020.

[13] R. Van Coile, D. Hopkin, N. Elhami-Khorasani, D. Lange en T. Gernay, „Permanent and live load model for probabilistic structural fire analysis: a review," Minneapolis, 2019.

[14] S. Selamet en E. Akcan, „Reliability risk assessment in high rise buildings in case of fire,” Brisbane, 2015.

[15] FPS Interior, „Annex 6 - Industrial buildings,” in Royal decree to point out the regulations for the prevention of fire and explosions for new buildings, Brussels, Moniteur Belge - Belgisch staatsblad, 2009, pp. 49369-49397.

[16] EN 1993-1-1, Eurocode 3 - Design of steel structures: Part 1-1: General rules and rules for buildings, Brussels: CEN, 2003.

[17] A. Ghali en A. M. Neville, Structural analysis a unified classical and matrix approach, 3rd red., London - New York: Chapman and Hall, 1989.

[18] JCSS, „Probabilistic Model Code,” https://www.jcss.byg.dtu.dk, Denmark, 2001.

[19] M. Holicky en M. Sykora, „Stochastic models in analysis of structural reliability,” Beer (Israel), 2010.

[20] EUR 28906, „Standardization of safety assessment procedures across brittle to ductile failure modes,” European commission, Directorate-General for Research and Innovation, Luxembourg, 2017.

[21] T. Molkens en B. Rossi, „Mode Based Reliability Approach for Single Bay Portal Frames,” Journal, p. To be submitted, 2020.

[22] A. H. Buchanan en A. K. Abu, Structural design for fire safety, 2nd red., Chichester: John Wiley \& Sons Inc., 2017.

[23] S. Reitgruber, C. Pérez-Jimenez, C. Di Blasi en J.-M. Franssen, „Some comments on the parametric fire model of Eurocode 1," Jordanstown, 2006.

[24] J.-M. Franssen en R. Zaharia, Design of steel structures subjected to fire, Liège: Les éditions de l'université de Liège, 2005.

[25] T. Molkens en B. Rossi, „On the simulation of real fire for post-fire resistance evaluation of steel structures,” Fire Technology, p. Under review, 2020.

[26] C. Roberts, „Monte Carlo methods in statistics,” Hal.archive-ouvertes.fr, p. 00412639, 2009.

[27] M. Sykora, D. Diamantidis, M. Holicky en K. Jung, „Target reliability levels for existing structures considering economic and societal aspects," Structure and Infrastructure Engineering, nr. 13, pp. 181-194, 2017.

[28] R. Caspeele, M. Sykora, D. L. Allaix en R. Steenbergen, „,The design value method and adjusted partial factor approach for existing structures,” Structural Engineering International, vol. 23, nr. (4), pp. 386-393, 2013.

[29] ISO 2394, General principles on reliability for structures, Geneva: International standard organization, 2015.

[30] fib bulletin 80, Partial factor methods for existing structures, Lausanne: Fédération intenationale bu béton, 2016.

[31] EN 1990, Eurocode 0 - Basis of structural design, Brussels: CEN, 2002. 